\title{
Diffuse biogenic load from the catchment area of small watercourses
}

\author{
Evgeni Nesterov ${ }^{1,}$, Grigori Frumin ${ }^{2}$, Pavel Egorov ${ }^{1}$, and Alexander Lyubimov ${ }^{1}$ \\ ${ }^{1}$ Herzen State Pedagogical University of Russia, Geology and Geoecology Department, 198328 \\ Saint Petersburg, Russian Federation \\ ${ }^{2}$ Russian State Hydrometeorological University, Ecology and Bioresources Department, 195196 \\ Saint Petersburg, Russian Federation
}

\begin{abstract}
The article systematizes information on quantitative parameters for assessing the modules of the background runoff of nutrients (total phosphorus and total nitrogen) with the catchment of rivers and lakes. A new approach proposed for estimating the modules of the background runoff of nutrients based on mathematical models. A methodology for calculating the modules of the background runoff of nutrients from the catchments of the rivers of the Baltic Sea basin developed. The study of the dependence of the trophic level of the water reservoir on the amount of phosphorus and nitrogen entering it led to the development of the so-called load concept, which is based on the idea of the existence of a quantitative relationship between the amount of phosphorus intake and the reaction of the reservoir. The maximum allowable export to the Gulf of Finland is $4860 \mathrm{t} / \mathrm{year}$ of total phosphorus and $106680 \mathrm{t} / \mathrm{year}$ of total nitrogen. These values significantly exceed the total load on the Novaya river from its catchment area: $0.072 \mathrm{t} /$ year for total phosphorus and $0.066 \mathrm{t} / \mathrm{year}$ for total nitrogen.
\end{abstract}

\section{Introduction}

Irresponsible attitude to the ecology of small rivers exacerbates the already serious problem of water on the Earth, the problem that can be generally formulated as a contradiction between the increasing public demand for high quality water, on the one hand, and its continuing deterioration, on the other. This deterioration is most significantly connected with chemical water pollution. The result of this is usually a change in the position of the reservoir on the trophic scale. The importance of the problem of water pollution is so great that the justification of its relevance seems to be a conscious necessity. The study of diffuse pollution of any water body inevitably covers a set of processes of interaction of surface and underground waters in the catchment area with the regime of anthropogenic influence. The object of consideration is usually a catchment area, as a territorial unit that combines local landscapes. In scientific research and design practice, mathematical modeling is the most effective tool for analyzing the processes of diffuse pollution of water objects and water ecosystems [9].

\footnotetext{
* Corresponding author: nestem26@mail.ru
} 
In the course of the research, an assessment of the diffuse biogenic load from the catchment area of the river Novaya on the river Novaya was made. The upper reaches and part of the middle course of the river are in an area of intensive agriculture. Agricultural land covers 2900 hectares, $90 \%$ of the total amount of which are arable land of 2,600 hectares. This category of land represents a certain danger for the hydraulic system due to possible flushing of the treated soil into the system of hydromelioration and therefore in the Novaya riverbed. Fields are a source of systematic ingress of chemical elements into the hydraulic system, along with the rain-washing out of fertilizers and pesticides. Objects in urbanized areas and allotments have a significant impact on the state of the river. Urbanized objects absolutely dominate the catchment area and occupy $2 / 3$ of its area. Almost $54 \mathrm{~km}^{2}$ of the administrative district is occupied by urban-type buildings and less than $2 \mathrm{~km}^{2}$ is occupied by rural settlements, while $0.5 \mathrm{~km}^{2}$ is covered by individual buildings and structures, which is 65.2 and $0.6 \%$, respectively.

The Novaya river catchment area (Fig. 1) is located in the South-Western part of the Kirovsky district of Saint Petersburg and the adjacent part of the Krasnoselsky district.

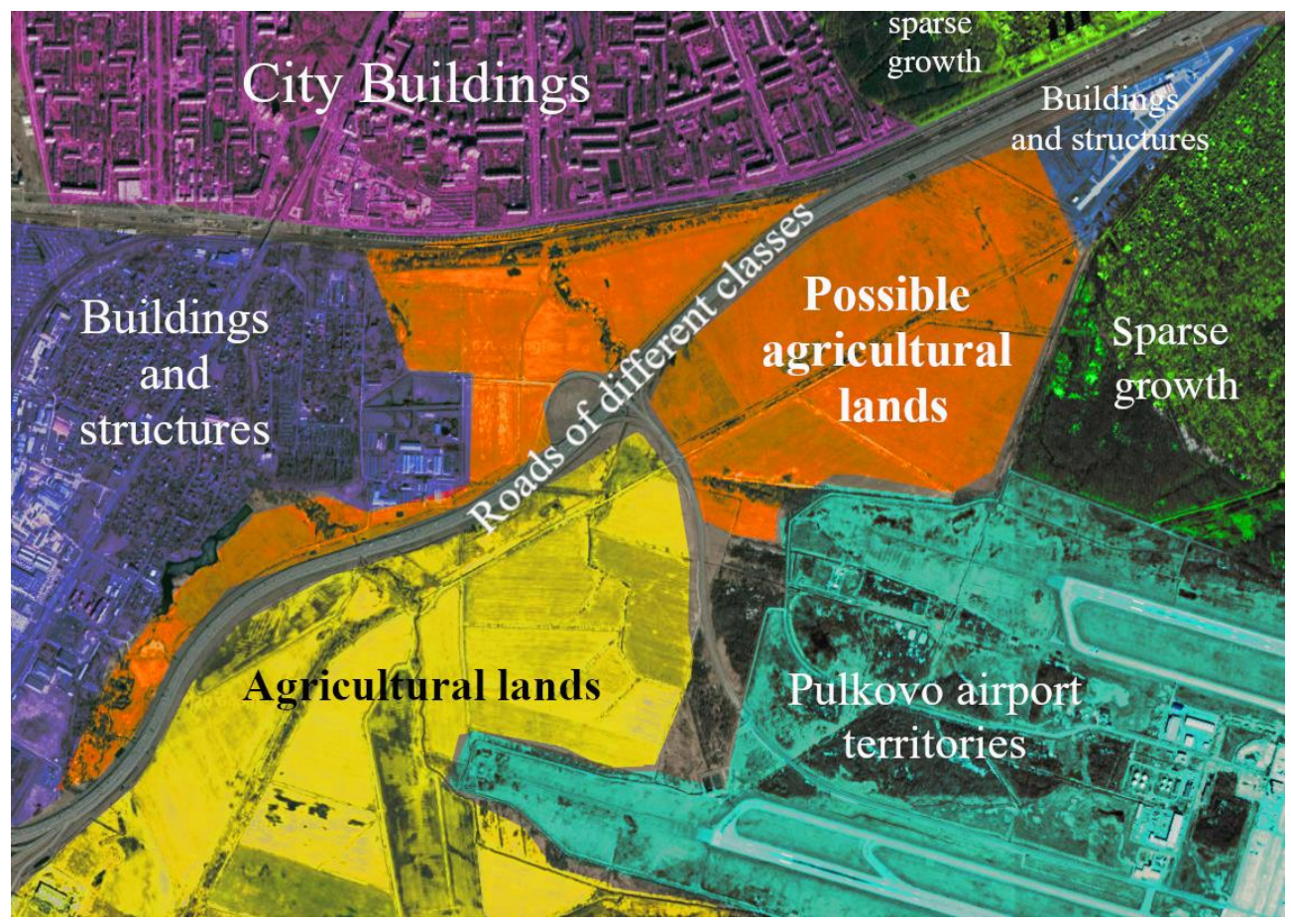

Fig. 1. Results of the initial interactive classification of the Novaya river catchment area by land category

The indicators that characterize the catchment area: the catchment area is $9.7 \mathrm{~km}^{2}$; the water area of ponds-overflows within the Kirovsky district of St. Petersburg is $0.1 \%$; the catchment area includes megalopolis land $-65.1 \%$; other settlements $-0.03 \%$; industrial and other special purpose land - $0.27 \%$; agricultural land $-34.9 \%$; forest land $-2.1 \%$; railways - $15 \mathrm{~km}$; ring motorway $-11.4 \mathrm{~km}$; other highways $-25 \mathrm{~km}$; field roads, forest and other special purpose roads $-28 \mathrm{~km}$. To solve the problem of water flow in the Novaya river, the following equation was applied [8]:

$$
R=0.0089 \cdot F,
$$


where $\mathrm{R}$ is the water flow for the catchment area $=500 \mathrm{~m}^{3} /\left(\mathrm{s} \mathrm{km}^{2}\right)$; F is the catchment area, $\mathrm{km}^{2}$. For the Novaya river, $F=9.7 \mathrm{~km}^{2}$. Then the average annual flow rate $\mathrm{R}=0.091 \mathrm{~m}^{3} / \mathrm{s}$. There are fairly close links between the basin area and the length of the main river:

$$
F=a L n,
$$

where a and $\mathrm{n}$ are geographical parameters. For example, for the European part of Russia, $\mathrm{a}=0.58, \mathrm{n}=1.75$. The length of the Novaya river is $\mathrm{L}=5 \mathrm{~km}$, then $\mathrm{F}=9.7 \mathrm{~km}^{2}$. This value was used in subsequent calculations.

\section{Research materials and methods}

Several indicators were used for calculations. The first indicator is the data on the content of phosphorus $\left(\mathrm{P}_{2} \mathrm{O}_{5}, \%\right)$ in the soils of the Novaya river catchment area. 120 samples were selected and analyzed for the phosphorus content (the area of one site is $100 \mathrm{~m}^{2}$ ). Statistical processing of the analysis results showed the following: the average $\mathrm{P}_{2} \mathrm{O}_{5}$ content is $0.206655 \%$, the maximum is $0.482022 \%$, the minimum is $0.097119 \%$, and the standard error is $0.0739 \%$. As a result of recalculation, it was found that the surveyed soils of the Novaya river catchment area $\left(0.012 \mathrm{~km}^{2}\right)$ contain $0.108 \mathrm{~kg}$ of phosphorus $(0.09 \%$ of phosphorus). The phosphorus content in the soils of the entire catchment area of the Novaya river $\left(9.7 \mathrm{~km}^{2}\right)$ is approximately 0.087 tons.

According to [3], sod-podzolic, predominant-light loamy and medium loamy soils contain $0.14-0.16 \%$ of phosphorus. Sod-podzolic light loamy soils developing on moraine loam $-0.09-0.12 \%$ of phosphorus. Sod-podzolic sandy loams, underlain by moraine loams, - $0.07-0.12 \%$ of phosphorus. Sod-podzolic sandy soils $-0.06-0.08 \%$. The following approach was used to estimate the nitrogen content in the soils of the Novaya river catchment area. Concentrations of 15 chemical elements containing in catchment soils were compared with their abundance in soils (clarkes) (Table 1).

Table 1. Content of chemical elements in soils of the Novaya river catchment area (C) and clarkes, $\mathrm{mg} / \mathrm{kg}$.

\begin{tabular}{|c|c|c|c|c|c|}
\hline Element & Clarke & Content & Element & Clarke & Content \\
\hline $\mathrm{S}$ & 850 & 442.6 & $\mathrm{Ga}$ & 30 & 14.8 \\
\hline $\mathrm{Sc}$ & 7 & 9.27 & $\mathrm{As}$ & 5 & 3.2 \\
\hline $\mathrm{V}$ & 100 & 85.6 & $\mathrm{Rb}$ & 100 & 125.7 \\
\hline $\mathrm{Cr}$ & 200 & 52.9 & $\mathrm{Sr}$ & 300 & 154.5 \\
\hline $\mathrm{Co}$ & 8 & 6.92 & $\mathrm{Ba}$ & 500 & 654.9 \\
\hline $\mathrm{Ni}$ & 40 & 23.3 & $\mathrm{La}$ & 40 & 49.1 \\
\cline { 1 - 2 } $\mathrm{Cu}$ & 20 & 23.1 & $\mathrm{~Pb}$ & \multirow{2}{*}{10} & 28.5 \\
\hline $\mathrm{Zn}$ & 50 & 86.4 & $\mathrm{~Pb}$ & \\
\hline
\end{tabular}

According to the data shown in Table 1.1, the following dependence was established (equation 3, Fig. 2):

$$
\ln \mathrm{C}=0.401+0.865 \ln [\text { clarke], }
$$

$\mathrm{n}=15 ; \mathrm{r}=0.926 ; \mathrm{r}^{2}=0.857 ; \sigma \mathrm{y}(\mathrm{x})=0,584 ; \mathrm{F}_{\mathrm{p}} / \mathrm{F}_{\mathrm{T}}=17.0$. Here $\mathrm{n}$ is the quantity of chemical elements, $r-$ the correlation coefficient, $r^{2}-$ the coefficient of determination, $\sigma y(x)-$ the standard error, $\mathrm{F}_{\mathrm{p}} / \mathrm{F}_{\mathrm{T}}$ - the ratio of the calculated value of the Fisher criterion to the table value at the $95 \%$ of the significance level. The mathematical model (1) is adequate $\left(\mathrm{F}_{\mathrm{p}}>\mathrm{F}_{\mathrm{T}}\right)$ and can be used to predict the content of other chemical elements in the Novaya river catchment soils, since $\mathrm{Fp} / \mathrm{F}_{\mathrm{T}}>4$. 
The prevalence of nitrogen in soils is $1000 \mathrm{mg} / \mathrm{kg}$. Substituting this value in the formula (3), we get the content of this element in the soils of one sample of the Novaya river catchment area $588 \mathrm{mg} / \mathrm{kg}(0.061 \%)$, and for the entire catchment - about 0.057 tons. This result should be regarded as purely indicative and requiring an experimental verification. The total amount of nitrogen in soils varies from $0.02-0.05 \%$ in sod-podzolic sandy soils to $0.2-0.5 \%$ in chernozems (black earth).

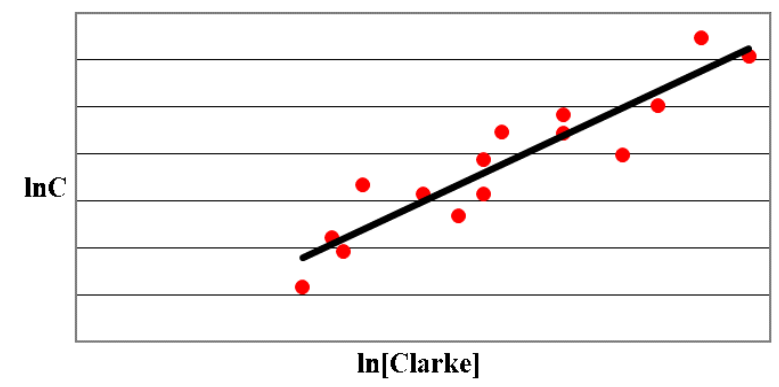

Fig. 2. Relationship between the chemical elements content in the soils of the Novaya river catchment area (C) and the clarkes

Another way to estimate the nitrogen content in the Novaya river catchment area is based on the abundance of nitrogen in soils. The average nitrogen content in one soil sample is $1000 \mathrm{mg} / \mathrm{kg}$, and in the entire catchment area (97,000 samples) is $0.097 \mathrm{t}$. The second indicator used for calculations is the amount of precipitation (Fig. 3). The total amount of precipitation in St. Petersburg in 2018 was $530 \mathrm{~mm}$. As a rule, most of the biogenic substances received in the catchment from various sources do not reach the closing sections of large rivers, as they are held by the catchment and various links of the hydrographic network. As a result, the total load on the water object is only a part of the biogenic supply to the catchment areas.

The calculations were performed using the ILLM - Institute of Limnology Load Model (Certificate of state registration No. 2014612519 dated 27.02.2014), developed at the Institute of lake science of the Russian Academy of Sciences on the basis of domestic and foreign experience in modeling the removal of biogenic substances from catchment areas $[1,7]$, as well as HELCOM recommendations for assessing the load on water objects in the Baltic sea basin [4]. The model is designed to solve problems related to the quantitative assessment of the biogenic load generated by point and dispersed sources of pollution, and the forecast of its change under the influence of possible anthropogenic and climatic changes. The result of the simulation is a quantitative assessment of the load on the water reservoir from the catchment area and its individual components. The dispersed (diffuse) load is formed by the removal of substances from the entire catchment area. This is the emission of chemicals from the soil, washing away surface contaminants. In [2], an empirical model developed at the Institute of water ecology and inland fish farming in Germany was used to calculate the retention of chemicals by catchments and their hydrographic network. 


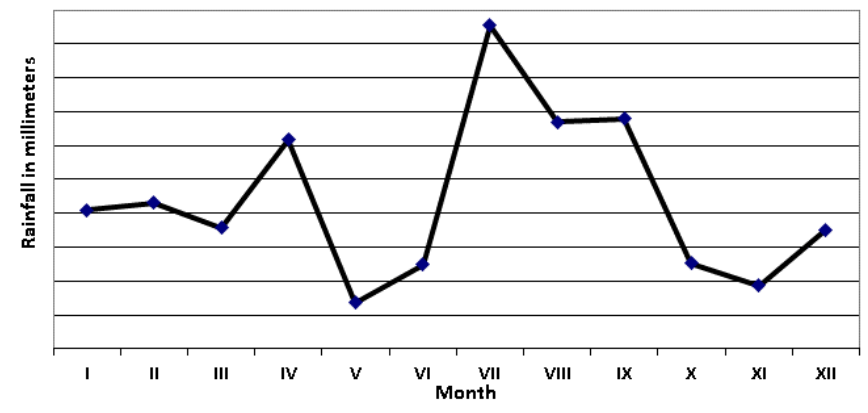

Fig. 3. Dynamics of the annual precipitation in Saint Petersburg in 2018

An increase in the area of water objects, expressed as a \% of the total catchment area, leads to an increase in the retention of biogenic elements and, accordingly, to a decrease in the values of removal of substances from the catchment. At the same time, an increase in runoff leads to both an increase in the emission of substances from the soil and a decrease in the retention of biogenic elements by water bodies in the catchment area. It is possible to estimate the retention of chemicals by the catchment and the riverbed network dependence on the characteristics of the flow and the size of the catchment. If the catchment area under study is characterized by high value of water surface share in the total catchment area, then it is appropriate to apply the ratio for calculations.

The values of the empirical parameters $a_{1}, b_{1}, a_{2}$ and $b_{2}$ are set in accordance with the data in Table $2[1,6]$.

Table 2. The values of the empirical parameters

\begin{tabular}{|c|c|c|c|c|c|}
\hline Element & Catchment area & $\mathbf{a}_{1}$ & $\mathbf{b}_{1}$ & $\mathbf{a} 2$ & $\mathbf{b}_{2}$ \\
\hline \multirow{3}{*}{$\begin{array}{c}\text { Phosphorus } \\
\text { total }\end{array}$} & For all catchments & 26.6 & -1.71 & 13.3 & -0.93 \\
\cline { 2 - 6 } & $<1000 \mathrm{~km}^{2}$ & 41.4 & -1.93 & 57.6 & -1.26 \\
\cline { 2 - 6 } & $1000-10000 \mathrm{~km}^{2}$ & 21.7 & -1.55 & 9.3 & -0.81 \\
\cline { 2 - 6 } & $>10000 \mathrm{~km}^{2}$ & 28.9 & -1.80 & 26.9 & -1.25 \\
\hline Nitrogen total & For all catchments & - & - & 1.9 & -0.49 \\
\hline Nitrogen total & For lakes & - & - & 7.28 & -0.49 \\
\hline
\end{tabular}

For the Novaya river catchment area $\mathrm{W}=0.1 \%$, and atmospheric phosphorus fallouts are insignificant. These indicators were excluded in the calculations. Cnat values are given in Table 3 [2]. Forest lands in the Novaya river catchment area make up $2.1 \%$ or $0.2 \mathrm{~km}^{2}$.

Table 3. Phosphorus concentrations $(\mathrm{mg} / \mathrm{l})$ in soil waters and primary links of the hydrographic network for various types of underlying surface

\begin{tabular}{|c|c|c|c|c|}
\hline $\begin{array}{c}\text { Underlying } \\
\text { surface }\end{array}$ & $\begin{array}{c}\text { Mixed } \\
\text { territories }\end{array}$ & $\begin{array}{c}\text { Natural } \\
\text { territories }\end{array}$ & $\begin{array}{c}\text { Agricultural } \\
\text { lands }\end{array}$ & Urbanized territories \\
\hline Phosphorus & 0.12 & 0.05 & 0.08 & 0.20 \\
\hline
\end{tabular}

The modulus of phosphorus removal $\left(\mathrm{kg} /\left(\mathrm{km}^{2} /\right.\right.$ year $)$ from the catchment is $\mathrm{L} /(1000 \mathrm{~A})$, and its background (natural) component is Lnat/(1000 A).

\section{Research results}

Calculation of the flow modulus: $\mathrm{q}=0.03171 \mathrm{y}=0.03171 \cdot 530=16.8$.

Calculation of total phosphorus removal coefficient (Table 2): $R_{t}=1-R_{r}=1 /(1+$ $\left.\mathrm{a}_{1} \mathrm{q} \mathrm{b}_{1}\right)=1 /(1+26.6 \cdot 16.8-1.71)=0.82$. Calculation of the total phosphorus load on the 
Novaya river from the catchment area: $L_{P}=R_{t} \cdot L_{\text {tot }}=0.0873 \cdot 0.82=0.072 \mathrm{t} /$ year. Calculation of the background component of the total phosphorus load on the Novaya river (Table 3): $\mathrm{L}_{\text {nat }}=(1-\mathrm{R})\left[\mathrm{L}_{\mathrm{a}}+\mathrm{Cnat} \cdot \mathrm{y} \cdot(\mathrm{A}(1-\mathrm{W} / 100) / 1000]=(1-0.18)[0.12 \cdot 530 \cdot(0.2 / 1000)]=\right.$ $0.010 \mathrm{t} /$ year. Calculation of the total nitrogen removal coefficient (table 2$): \mathrm{R}_{t}=1-\mathrm{R}_{\mathrm{r}}=$ $1 /\left(1+\mathrm{a}_{1} \mathrm{q} \mathrm{b}_{1}\right)=1 /(1+1.9 \cdot 16.8-0.49)=0.68$. Calculation of the total nitrogen load on the Novaya river from the catchment area: $\mathrm{L}_{\mathrm{N}}=\mathrm{R}_{\mathrm{t}} \cdot \mathrm{L}_{\mathrm{tot}}=0.097 \cdot 0.68=0.066 \mathrm{t} / \mathrm{year}$. The results of the study are summarized in Table 4.

Table 4. Diffuse biogenic load from the catchment of the Novaya river

\begin{tabular}{|c|c|c|c|}
\hline Biogenic element & $\begin{array}{c}\text { Total load, } \\
\text { kg/year }\end{array}$ & $\begin{array}{c}\text { Background load } \\
\text { kg/year }\end{array}$ & $\begin{array}{c}\text { Anthropogenic load, } \\
\text { kg/year }\end{array}$ \\
\hline Phosphorus total & 72 & 10 & 62 \\
\hline Nitrogen total & $66^{*}$ & - & - \\
\hline $\mathrm{Zn}$ & 50 & 86,4 & \\
\hline
\end{tabular}

Note. ${ }^{*}$ The result should be considered as indicative.

In work [8], the maximum allowable input (export) and maximum allowable runoff modules of biogenic elements in the Baltic Sea subequatorial are given. The maximum allowable export to the Gulf of Finland is $4860 \mathrm{t} /$ year of total phosphorus and $106680 \mathrm{t} / \mathrm{year}$ of total nitrogen. These values significantly exceed the total load on the Novaya river from its catchment area: $0.072 \mathrm{t} /$ year for total phosphorus and $0.066 \mathrm{t} / \mathrm{year}$ for total nitrogen.

\section{Conclusion}

The main sources of pollution of reservoirs with biogenic substances are the flushing of nitrogen and phosphorus fertilizers from fields, the construction of water reservoirs without proper cleaning of the bed, and the discharge of waste waters, including those that have undergone biological treatment. The assessment of the diffuse biogenic load from the Novaya river catchment to the Novaya river showed that the upper reaches and part of the middle course of the river are in the zone of intensive agriculture. This category of land represents a certain danger to the hydraulic system due to the possible flushing of the treated soil into the hydro-reclamation system and, consequently, into the bed of the Novaya river. Fields are a source of systematic ingress of chemical elements into the hydraulic system along with the washing out of fertilizers and pesticides by rain. Objects in urbanized areas and allotments have a significant impact on the state of the river. Urbanized objects absolutely dominate the catchment area and occupy $2 / 3$ of its area. Almost $54 \mathrm{~km}^{2}$ of the administrative area is covered by urban-type buildings and less than $2 \mathrm{~km}^{2}$ is occupied by rural settlements, while $0.5 \mathrm{~km}^{2}$ is covered by individual buildings and structures, which is 65.2 and $0.6 \%$, respectively. The maximum allowable export to the Gulf of Finland is 4860 t/year of total phosphorus and 106680 t/year of total nitrogen. These values significantly exceed the total load on the Novaya river from its catchment area: $0.072 \mathrm{t} /$ year for total phosphorus and $0.066 \mathrm{t} /$ year for total nitrogen.

\section{References}

1. H. Behrendt, D. Opitz. Hydrobiology, Retention of nutrients in river systems: dependence on specific runoff and hydraulic load, 410, 111-122 (1999).

2. S. Kondratiev, S. Golosov, I. Zverev, V. Ryabchenko, A. Dvornikov, Modeling abiotic processes in the catchment system - reservoir (on the example of Lake Peipsi - Pskov), 
104 (Nestor Story Publishing House, Saint Petersburg, 2004).

3. V. Mineeva, Agrochemistry: Textbook, 720 (MSU Publishing House, Moscow, 2004).

4. Guidelines for the compilation of waterborne pollution to the Baltic Sea (PLC-water), 80 (HELCOM, Helsinki 2005).

5. S. Kondratiev, The formation of the external load on water bodies: modeling problems, 255 (Science Publishing House, Saint Petersburg, 2007).

6. H. Behrendt, R. Dannowski. Nutrients and heavy metals in the Odra River system. Weissensee Verlag Publ., Germany, 337 (2007).

7. S. Kondratiev, M. Kazmina, M. Shmakova, E. Markova, Regional ecology, 3-4, 50-59 (2011).

8. G. Frumin, Calculation of permissible nutrient load on transboundary water bodies. 27 (Russian State Hydrometeorological University, Saint-Petersburg, 2013).

9. L. Ratcovitch, V. Markin, I. Glazunova, S. Sokolova, Construction and architecture, 3, 64-75 (2016).

10. E. Nesterov, P. Egorov, M. Markova, D. Morozov. SGEM, 19, 699-707 (2019). 